\title{
Effect of heat treatment on mechanical properties and susceptibility to stress corrosion cracking of aluminium alloy
}

\begin{abstract}
The effect of the retrogression and reaging (RRA) heat treatment on the correlation between microstructure, mechanical properties and susceptibility to stress corrosion cracking (SCC) of the 6061-T6 aluminium alloy in dry air and sprayed in 3.5\% $\mathrm{NaCl}$ solution has been studied. The as-received T6 alloy was subjected to retrogression at temperature $200^{\circ} \mathrm{C}$ for 10 minutes, quenching for 30 seconds and reaging at temperature $180^{\circ} \mathrm{C}$ for $24 \mathrm{~h}$. In this study, the effect of RRA on mechanical properties of the as-received 6061-T6 alloy was investigated by tensile test in air and sprayed in $3.5 \% \mathrm{NaCl}$ solution. Alternate immersion preparation was conducted to expose the as-received 6061-T6 alloys and RRA heat treated alloys into the corrosive environment, $3.5 \% \mathrm{NaCl}$ solution for 20 days. The susceptibility to SCC was investigated by direct tension stress-corrosion (DTSC) tests sprayed in a 3.5\% $\mathrm{NaCl}$ solution at crosshead speed of $0.2 \mathrm{~mm} / \mathrm{min}$; the loss of elongation (ELloss) was taken into account for the susceptibility to SCC. Generally, the RRA heat treatment improves the mechanical properties including yield strength, ultimate tensile strength and ductility. On the other hand, the RRA heat treatment decreases the susceptibility to SCC.
\end{abstract}

Keyword: Aluminium alloy; Reaging; Retrogression; Stress corrosion cracking 